Article

\title{
A Novel Cyclodextrin-Functionalized Hybrid Silicon Wastewater Nano-Adsorbent Material and Its Adsorption Properties
}

\author{
Jing Li ${ }^{1,2,3}\left(\mathbb{D}\right.$, Chao Qiu ${ }^{1,2,3}$, Haoran Fan ${ }^{1,2,3}$, Yuxiang Bai ${ }^{1,3}$, Zhengyu Jin 1,2,3 and \\ Jinpeng Wang $1,2,3, *$ \\ 1 State Key Laboratory of Food Science and Technology, Jiangnan University, Wuxi 214122, China; \\ 18246037016@163.com (J.L.); 930017357@163.com (C.Q.); fanhaoran0622@163.com (H.F.); \\ ybai@jiangnan.edu.cn (Y.B.); fpcenter@jiangnan.edu.cn (Z.J.) \\ 2 School of Food Science and Technology, Jiangnan University, Wuxi 214122, China \\ 3 Synergetic Innovation Center of Food Safety and Nutrition, Jiangnan University, Wuxi 214122, China \\ * Correspondences: jpwang1984@jiangnan.edu.cn; Tel.: +86-159617681356 \\ Academic Editor: Bernard Martel \\ Received: 20 May 2018; Accepted: 13 June 2018; Published: 19 June 2018

\begin{abstract}
A novel cyclodextrin-functionalized hybrid silicon nano-adsorbent material (6-EA- $\beta$-CD-Si) was synthesized via the nucleophilic substitution method. The structure was detected by Fourier transform infrared (FT-IR), X-ray, thermogravimetric analysis, and Brunauer-Emmett-Teller (BET) analysis. Results reveal that the BET surface area of $6-E A-\beta-C D-S i$ is $240 \mathrm{~m}^{2} / \mathrm{g}$ and the average pore size is $4.16 \mathrm{~nm}$. The adsorption properties of 6-EA- $\beta-C D-S i$ onto methylene blue (MB) were studied and fitted with adsorption kinetic models. Both the Freundlich adsorption isotherm model and pseudo-second-order model were fitted with well shows that the multi-layer adsorption with chemisorption and physisorption co-existing in the system. The maximum adsorption capacities are $39.37,39.21,36.90$, and $36.36 \mathrm{mg} / \mathrm{g}$ at temperatures $303,313,323$, and $333 \mathrm{~K}$, respectively. The maximum removal rate of $\mathrm{MB}$ could reach $99.5 \%$, indicating the potential application value of 6 -EA- $\beta$-CD-Si in wastewater treatment. The adsorption mechanisms of $6-E A-\beta-C D-S i$ showed that the hydrophobic cave of $\beta-\mathrm{CD}$ plays an important role on the adsorption of $\mathrm{MB}$.
\end{abstract}

Keywords: $\beta$-cyclodextrin; hybrid silicon; nano-adsorbent material; adsorption

\section{Introduction}

Water pollution from small industries is a serious problem throughout the world [1]. Toxic dyeing effluents generated in the textile, dyestuffs, leather, papermaking, and plastics are genotoxic, carcinogenic, and teratogenic hazards to humans and pose a significant threat to human health [2]. Therefore, removing the dye in wastewater to an acceptable level before being discharged into the natural environment has been defined in many countries' laws. To date, a series of methods have been adopted, including catalytic degradation [3], biological treatment [4], chemical precipitation [5], membrane filtration [6], adsorption [7], and many other technologies to reduce the pollution and hazard to the environment caused by dye wastewater. However, each method has its own limitations. At present, the adsorption process is considered as one of the most effective and economical methods for removing pollutants from effluent due to its simplicity of design and ease of operation [8,9]. Some of easy acceptable adsorbent materials such as zeolite [10], graphene [11], metal oxides [12], magnetic particles [13], and activated carbon [14] have been chosen for removing dyes in wastewater. However, there are still some limitations for these materials being used widely because of slow adsorption rate, 
low adsorption capacity, and inconvenient separation [15]. Therefore, high selectivity, high adsorption capacity, long useful lifetime, and low-cost promising adsorbents are still in urgent need.

It is widely known that $\beta$-cyclodextrin ( $\beta-C D)$ is a commercial natural macrocycle molecule that contains a hydrophilic exterior and a hydrophobic internal cavity and has properties of non-toxicity and biodegradability due to its special structure and excellent chemical reactivity. $\beta-C D$ can form a complex with a wide range of organic and inorganic molecules, charged ions, and other groups in a solution by host-guest interactions through hydrophobic interactions and hydrogen-bonding interactions [16]. However, $\beta$-CD was hard to apply in wastewater directly because of its solubility in water. Fortunately, a large number of hydroxyl groups on the surface of $\beta-C D$ can undergo chemical reactions to improve its performance and to gain insoluble properties [17]. It has been used as a drug carrier [18], to remove metals [19] and organic compounds [20] from aqueous media, as well as in catalysis [21], and chromatography [22]. Therefore, they can also enable relatively facile synthesis of innovative materials for applications in the field of pollution removal from various compartments of the environment such as water, air and soil. However, the preparation steps of the traditionally modified cyclodextrin are quite complicated, with large amounts of reagents used, the cost is relatively high, and the yield of the intermediate product is low [23]. The latest application of nanomaterials in wastewater treatment provided us with the idea to construct a kind of structure in accordance with the nanoscale adsorbent based on the covalent immobilization of $\beta$-CD [24]. In this study, a new way was found to solve these problems by making a novel nanoparticle adsorbent.

The novel nanoparticle adsorbent was made by immobilization of $\beta-C D$ on hybrid silicon by the nucleophilic substitution method, with hybrid silicon inside as the core and $\beta$-CD as the "shell." The most important aspects for this novel material was that the $\beta$-CD shell should avoid the violent changes or even destruction of the cavity. Furthermore, the hybrid silicon as carrier and core play the role of immobilization and as an adsorbing material because of its large surface area, large pore volume, and good performance. Both the core and "shell" in this novel nanomaterial are capable of organic pollutants adsorption [25]. It can also overcome the problems of water-solubility, difficulties of recovery, and other defects and achieve a synergism effect between $\beta-C D$ "shell" and the carrier core [26]. The adsorption ability was evaluated for the treatment of methylene blue (MB) wastewater. This novel material combined the advantages of both hydrophobic cavity of $\beta-C D$ and high specific surface area of hybrid silicon, and it has the advantage of being environmentally friendly, having low costs in production, strong mechanical stability, and it is easy to separate from the wastewater.

\section{Results and Discussion}

\subsection{Structural Characterization}

The overall synthesis process is divided into three steps, and the corresponding synthetic route is shown in Scheme 1. The synthesis of 6-EA- $\beta-C D$ was achieved through the formation of ether linkage between hydroxyl group and halogen. The 6 -EA- $\beta$-CD-Si forms secondary amino groups via nucleophilic substitution. However, as a novel particle, the exact structure information was unknown. The linkage, crystallize, structure and geometry shape were detected as follows:

The formation of secondary amine groups is the key step in the synthesis of $6-\mathrm{EA}-\beta-\mathrm{CD}-\mathrm{Si}$. Thus, the Fourier transform infrared (FT-IR) spectra of $\beta-C D, 6-E A-\beta-C D, C l-S i$ and $6-E A-\beta-C D-S i$ are illustrated in Figure 1. Comparing the FT-IR spectra of $\beta-C D$ and $6-E A-\beta-C D$, the strong and broad peaks at around $3396 \mathrm{~cm}^{-1}$ are attributed to the $\mathrm{O}-\mathrm{H}$ stretching vibrations, and the peak becomes wider and broader on the FT-IR spectra of 6-EA- $\beta$-CD. The peaks at around $2900 \mathrm{~cm}^{-1}$ belong to the $\mathrm{C}-\mathrm{H}$ stretching vibrations, and the $\mathrm{N}-\mathrm{H}$ deformation vibration at around $1645 \mathrm{~cm}^{-1}$ appeared in 6-EA- $\beta$-CD for the existence of the primary amine groups. Meanwhile, the peaks at $1045 \mathrm{~cm}^{-1}$ were attributed to the $\mathrm{C}-\mathrm{O}-\mathrm{C}$ stretching vibrations, and the peaks at $1159 \mathrm{~cm}^{-1}$ corresponded to the C-C and C-O stretching vibrations [27]. The peak at $1367 \mathrm{~cm}^{-1}$ was attributed to the C-N stretching vibration, and red shift occurs on the FT-IR spectra of 6-EA- $\beta-C D$ due to the amine ethyl was grafted 
on $\beta-C D$, which verified that $6-E A-\beta-C D$ molecules were conjugated via the nucleophilic substitution method. Furthermore, comparing with the FT-IR spectroscopy of Cl-Si and 6-EA- $\beta-\mathrm{CD}-\mathrm{Si}$, the O-H stretching vibration in 6-EA- $\beta$-CD-Si become stronger due to the abundant hydroxyl group existing of $\beta$-CD molecules. The peaks at around $1160 \mathrm{~cm}^{-1}$ belong to the $C-C$ and $C-O$ stretching vibrations. The peak at $880 \mathrm{~cm}^{-1}$ corresponded to the bending vibration of the R-1,4-bond in $\beta$-CD. Meanwhile, the N-H deformation vibration at around $1655 \mathrm{~cm}^{-1}$ become stronger in 6-EA- $\beta$-CD-Si for the existence of the secondary amine groups. Thus, the FT-IR spectroscopy characterization proves that $\beta-C D$ is successfully immobilized on the surface of Cl-Si.

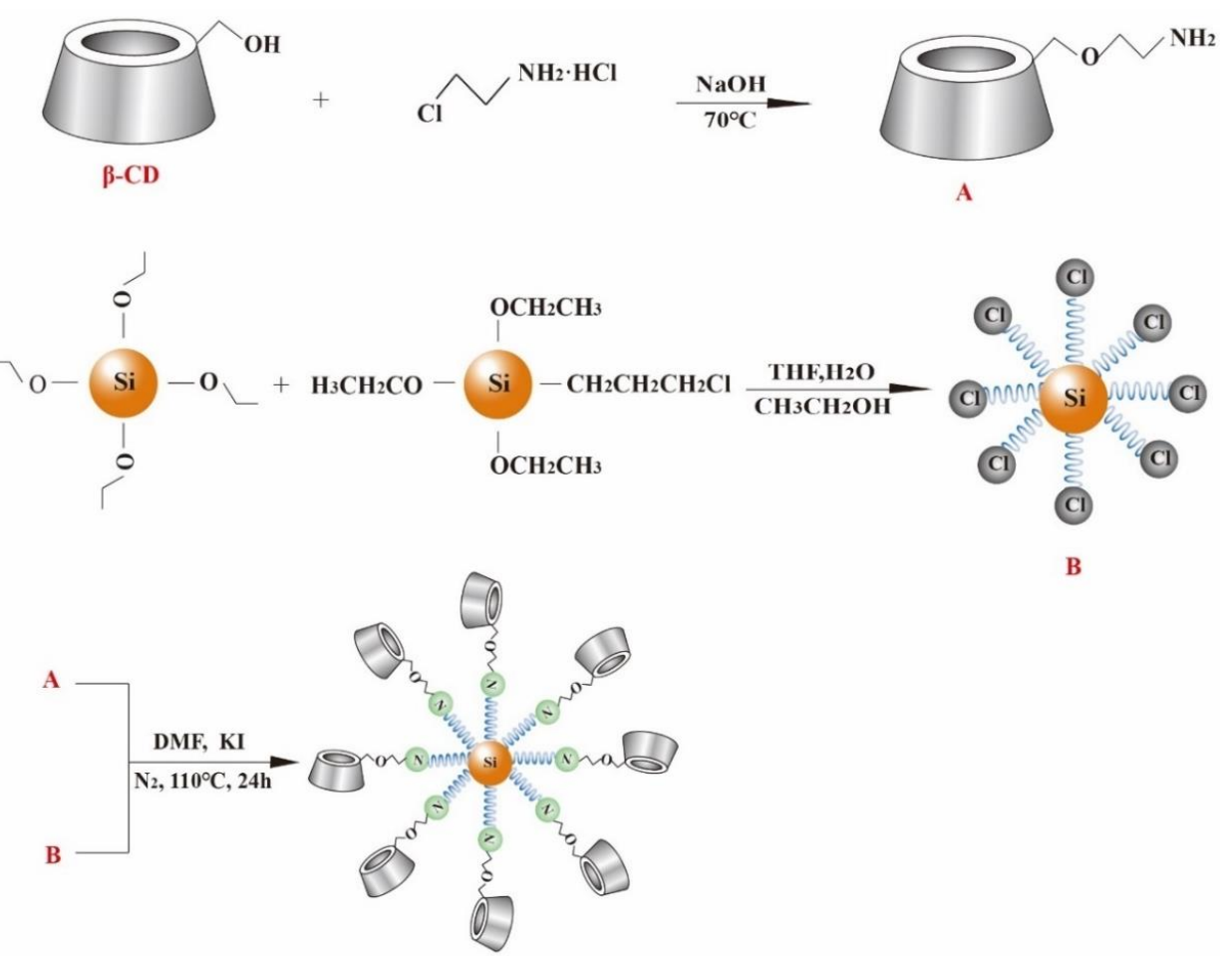

Scheme 1. Schematic representation of the preparation steps of 6 -EA- $\beta$-CD-Si.

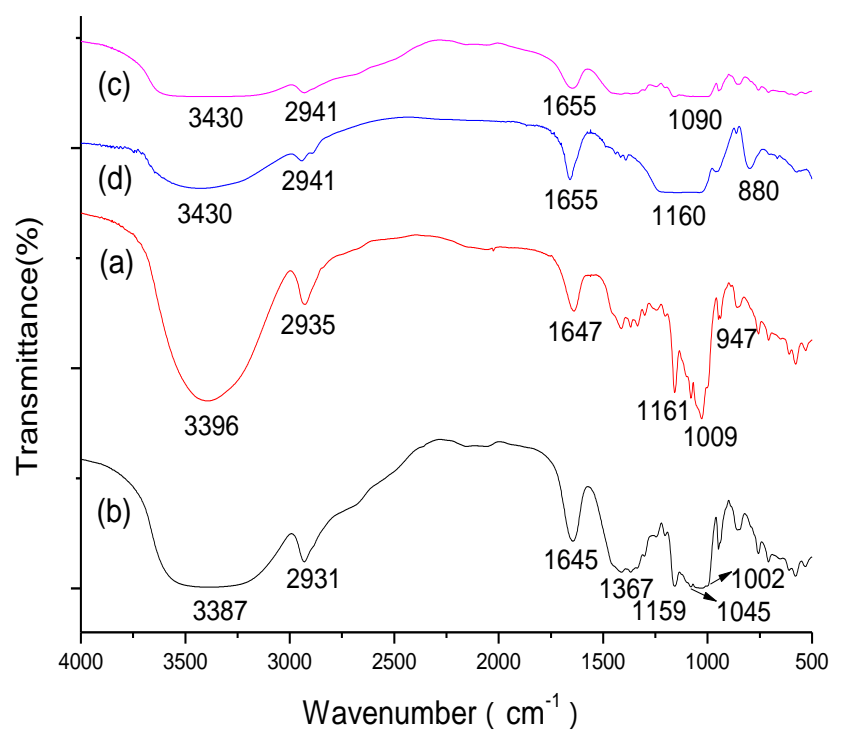

Figure 1. Fourier transform infrared (FT-IR) spectra of $\beta-\mathrm{CD}(\mathrm{a}), 6-\mathrm{EA}-\beta-\mathrm{CD}(\mathrm{b}), \mathrm{Cl}-\mathrm{Si}$ (c), and $6-\mathrm{EA}-\beta-\mathrm{CD}-\mathrm{Si}(\mathrm{d})$. 
According to the results of X-ray diffraction (XRD) (Figure 2), it can be derived that there are many characteristic diffraction peaks of $\beta-C D$ and $6-E A-\beta-C D$ in the range of $2 \theta=10-25^{\circ}$. These peaks are indicative of the presence of highly crystalline [28]. Meanwhile, it was found that the crystallization peak of 6-EA- $\beta-C D$ slightly lower than that of $\beta-C D$, which is due to the substitution of the aminoethyl group of $\beta$-CD by the aminoethyl group, and it is similar to the result of grafting citric acid on the surface of $\beta-C D$ to form cyclodextrin derivatives [29]. Meanwhile, it is noted that $\mathrm{Cl}$-Si and 6-EA- $\beta$-CD-Si have a wider peak shape in the range of $2 \theta=20-25^{\circ}$, which mainly shows the characteristic peak of $\mathrm{Cl}-\mathrm{Si}$. After 6-EA- $\beta-\mathrm{CD}$ is immobilized on the surface of $\mathrm{Cl}-\mathrm{Si}$, the overall peaks of $\mathrm{Cl}-\mathrm{Si}$ had almost not changed, mainly because $\beta-\mathrm{CD}$ is arranged in the monomolecular layer on the surface of $\mathrm{Cl}-\mathrm{Si}$ and there are not enough molecules to form $\beta-\mathrm{CD}$ crystal structures, so it is difficult to observe the $\beta$-CD characteristic peaks from the XRD of 6-EA- $\beta$-CD-Si. The X-ray diffraction characterization further proves that $\beta-\mathrm{CD}$ is successfully immobilized on the surface of $\mathrm{Cl}-\mathrm{Si}$.

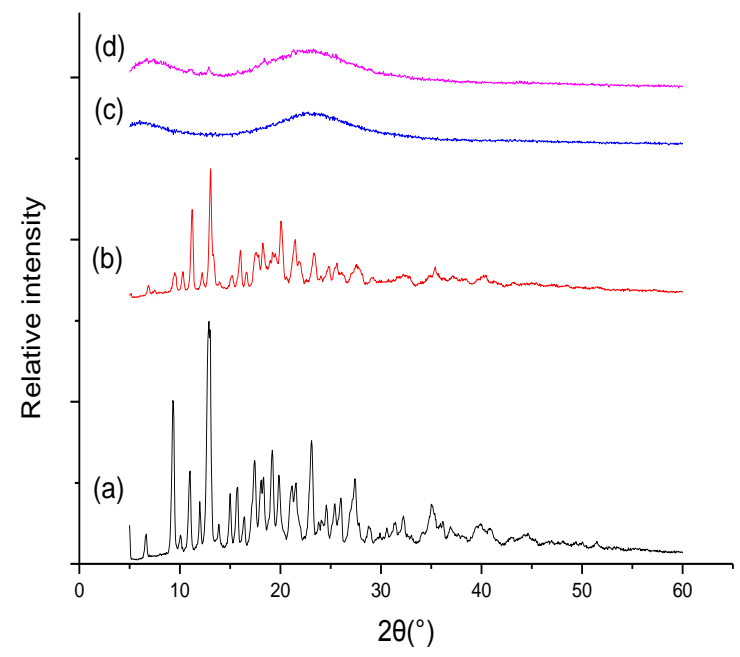

Figure 2. X-ray diffraction (XRD) spectra of $\beta-C D(a), 6-E A-\beta-C D(b), C l-S i(c)$ and 6-EA- $\beta$-CD-Si (d).

According to the TG curves (Figure 3), the weight loss before $150{ }^{\circ} \mathrm{C}$ comes from the moisture on the sample surface and inside the cavity of $\beta-\mathrm{CD}$. Comparing $\beta-\mathrm{CD}$ with 6-EA- $\beta-\mathrm{CD}$, the peak temperature of $6-\mathrm{EA}-\beta-\mathrm{CD}$ and the temperature corresponding to $50 \%$ weight loss of 6 -EA- $\beta-C D$ were lower than that of $\beta-C D$, which is mainly due to the higher disorder of the cyclodextrin molecules after grafting of the amine ethyl group on $\beta-C D$ [19]. Meanwhile, the reduction of the crystallinity of 6-EA- $\beta-\mathrm{CD}$ in the $\mathrm{X}$-ray spectrum also confirms this phenomenon. Compared to $\mathrm{Cl}-\mathrm{Si}$ and 6-EA- $\beta$-CD-Si, the weight loss of $\mathrm{Cl}-\mathrm{Si}$ was only $3 \%$ before $150{ }^{\circ} \mathrm{C}$, which is mainly due to the hydrophobic surface of $\mathrm{Cl}-\mathrm{Si}$, while the weight loss of 6-EA- $\beta-\mathrm{CD}-\mathrm{Si}$ was about $7 \%$ due to the partial decomposition of $\beta$-CD immobilized on the surface of $\mathrm{Cl}-\mathrm{Si}$. The overall mass loss of $\mathrm{Cl}-\mathrm{Si}$ in the range of $150-700{ }^{\circ} \mathrm{C}$ was $20.15 \%$, which is mainly due to the decomposition of CPTES, so it can be concluded that the organic layer on Cl-Si was about $20.15 \%$. The overall mass loss of 6-EA- $\beta$-CD-Si was $34.75 \%$, mainly due to the thermal decomposition of $\beta-\mathrm{CD}$ and $-\mathrm{CH}_{2} \mathrm{CH}_{2} \mathrm{CH}_{2-}$, it is inferred that the amount of $\beta-\mathrm{CD}$ immobilized on the surface of $\mathrm{Cl}-\mathrm{Si}$ is $34.75 \%$ (Neglecting $-\mathrm{CH}_{2} \mathrm{CH}_{2} \mathrm{CH}_{2}-$ thermal decomposition). From the TG curve, it can be further concluded that $6-\mathrm{EA}-\beta-\mathrm{CD}-\mathrm{Si}$ has a good thermal stability. 


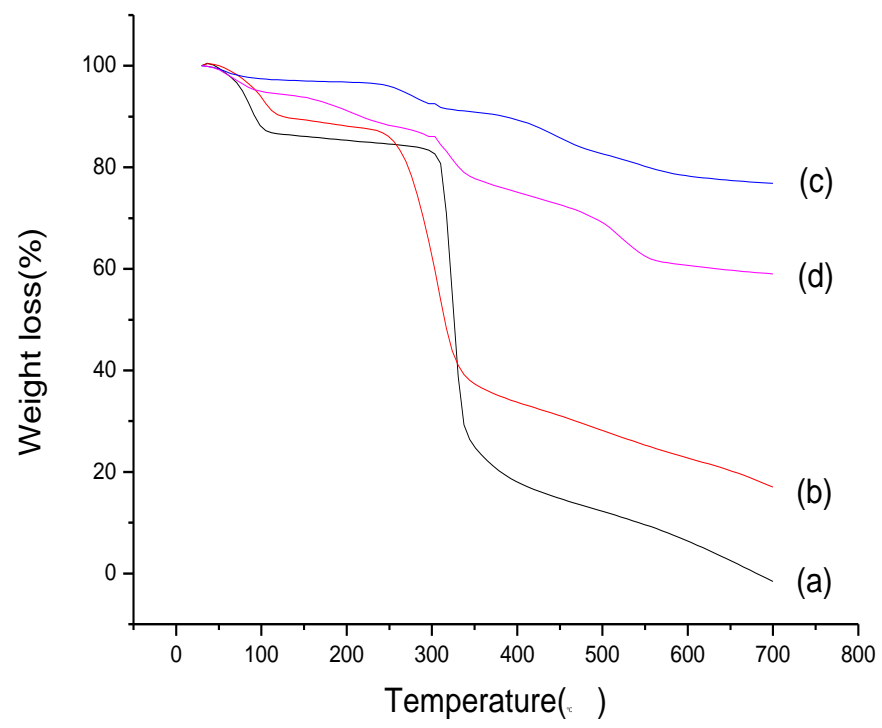

Figure 3. TG curves of $\beta-C D(a), 6-E A-\beta-C D(b), C l-S i(c)$ and 6-EA- $\beta-C D-S i(d)$.

The scanning electron microscopy (SEM) image and particle size of 6-EA- $\beta$-CD-Si are employed to characterize the shape and dimensions of 6 -EA- $\beta$-CD-Si (Figure 4). It can be clearly seen that 6-EA- $\beta$-CD-Si has a better spherical structure and a higher specific surface area, which increases the active sites of the guest molecules. In addition, the particle size of 6-EA- $\beta-C D-S i$ is mainly distributed in the range of $150-250 \mathrm{~nm}$, which is mainly due to the aggregation of nanoparticles. Exposed $\beta-C D$ and active sites on the surface of 6-EA- $\beta$-CD-Si may be better contacted with MB, which is conducive to adsorption.

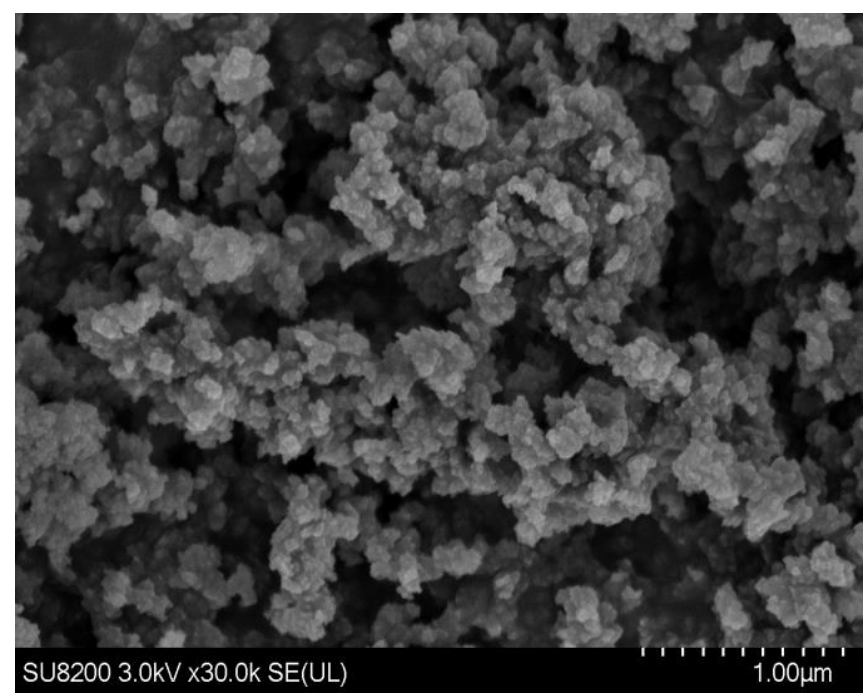

Figure 4. Scanning electron microscopy (SEM) images of 6-EA- $\beta-C D-S i$.

From the results of Brunauer-Emmett-Teller (BET) surface area (Figure 5), it can be seen the adsorption curve and the desorption curve are almost in a coincide state, indicating that $6-\mathrm{EA}-\beta-\mathrm{CD}-\mathrm{Si}$ has good adsorption properties. Meanwhile, $\beta-\mathrm{CD}, 6-\mathrm{EA}-\beta-\mathrm{CD}, \mathrm{Cl}-\mathrm{Si}$, and $6-\mathrm{EA}-\beta-\mathrm{CD}-\mathrm{Si}$ have been characterized in terms of BET surface area, hole volume, and pore size. Data are shown in Table 1. By comparison, 6-EA- $\beta-C D$ has higher BET surface area and lower hole volume and pore size than $\beta-C D$, further verifying the successful modification of amine-ethyl on the $\beta$-CD surface. In addition, the pore diameter of $6-\mathrm{EA}-\beta-\mathrm{CD}-\mathrm{Si}$ is larger than that of $\mathrm{Cl}-\mathrm{Si}$, further illustrating that $6-\mathrm{EA}-\mathrm{CD}-\mathrm{Si}$ 
has both the pore size characteristics of cyclodextrin and the high BET surface area characteristics of $\mathrm{Cl}-\mathrm{Si}$. It's noted that the BET surface area of 6-EA- $\beta$-CD-Si was $240.411 \mathrm{~m}^{2} / \mathrm{g}$ and average pore size is $4.162 \mathrm{~nm}$, and the pore size distribution of the product is mostly between 2 and $10 \mathrm{~nm}$, indicating that 6-EA- $\beta$-CD-Si belongs to a typical nanocomposite hole material. Compared with common adsorbent materials [30], the specific surface area of the two studies is the same, but this study has a higher adsorption capacity for MB. Compared with other cyclodextrin-modified materials [31], the specific surface area of the study can reach $919 \mathrm{~m}^{2} / \mathrm{g}$, but its maximum adsorption capacity is only $60 \mathrm{mg} / \mathrm{g}$. Thus, this novel material is conducive to adsorption, and the adsorption capacity of 6-EA- $\beta$-CD-Si is due to the existence of hydrophobic cavities and high specific surface area.

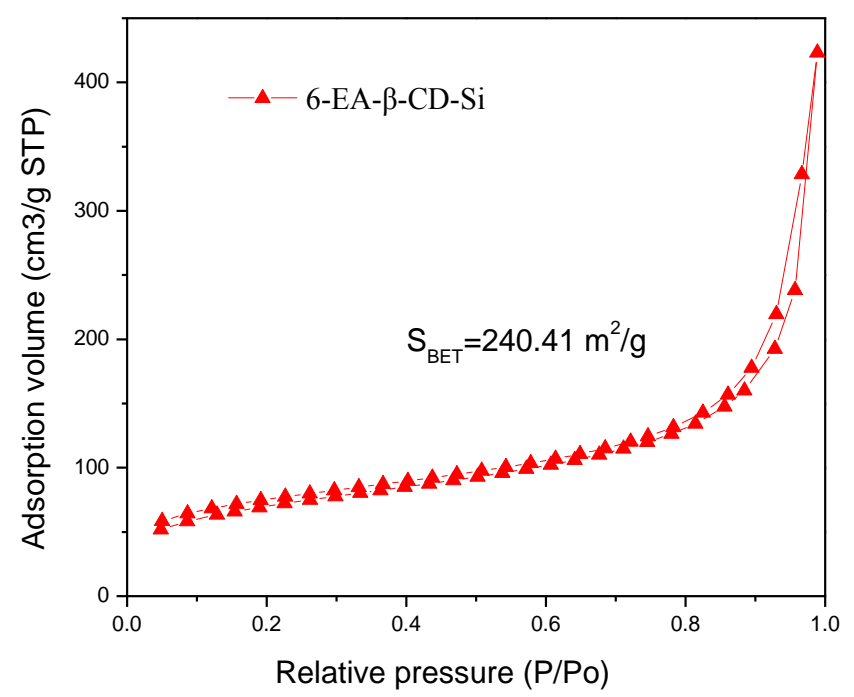

Figure 5. Brunauer-Emmett-Teller (BET) surface area of 6-EA- $\beta$-CD-Si.

Table 1. Micro-structure data of $\beta-C D, 6-E A-\beta-C D, C l-S i$, and $6-E A-\beta-C D-S i$.

\begin{tabular}{cccc}
\hline Material & BET Surface Area $\left(\mathbf{m}^{2} / \mathbf{g}\right)$ & Hole Volume $\left(\mathrm{cm}^{3} / \mathbf{g}\right)$ & Pore Size $(\mathbf{n m})$ \\
\hline$\beta-C D$ & 0.3445 & 0.0003 & 12.00 \\
6-EA- $\beta-C D$ & 0.3669 & 0.0002 & 10.80 \\
Cl-Si & 341.7485 & 0.2438 & 3.940 \\
6-EA- $\beta-C D-S i$ & 240.4112 & 0.3010 & 4.162 \\
\hline
\end{tabular}

\subsection{Adsorption Properties}

For the adsorption reaction, effective dosage, $\mathrm{pH}$, and initial $\mathrm{MB}$ concentration are the important factors affecting the adsorption of MB on 6-EA- $\beta-C D-S i$. Figure 6 a shows the effects of $6-E A-\beta-C D-S i$ dosage on the adsorption of MB. With the increase of the dose of $6-\mathrm{EA}-\beta-\mathrm{CD}-\mathrm{Si}$, the removal rate of $\mathrm{MB}$ increases, but the dose of 6-EA- $\beta$-CD-Si increases further, and the removal rate increases slightly. And the amount of adsorption decreased with the increase of the dose, which is mainly due to the fact the higher dose provides a large excess of active sites, resulting in a lower utilization of the site at a certain concentration of MB [16]. Meanwhile, 6-EA- $\beta$-CD-Si aggregation and competition will also affect the adsorption behavior between 6-EA- $\beta-\mathrm{CD}-\mathrm{Si}$ and MB. 

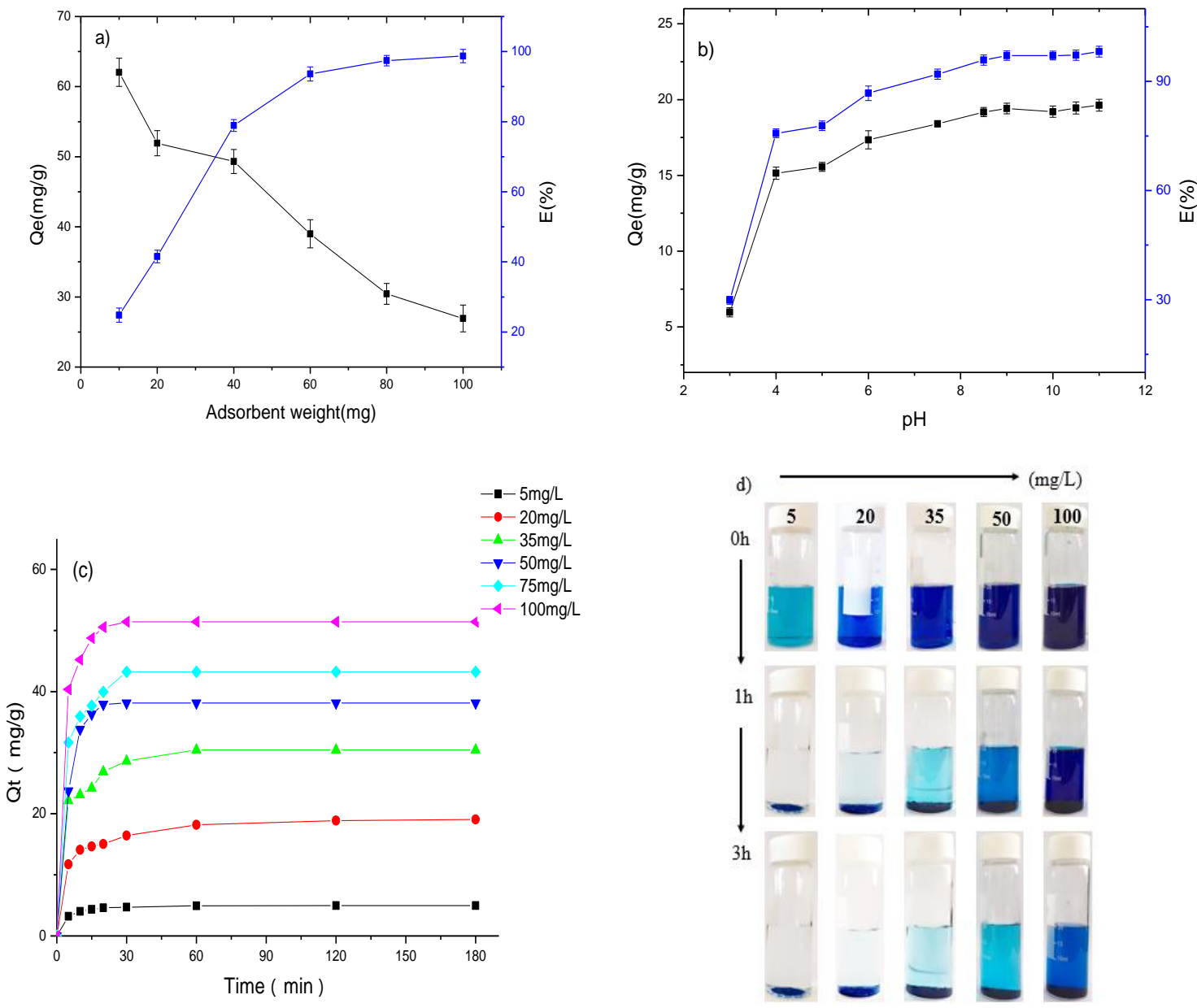

Figure 6. (a) Effective dosage of 6-EA- $\beta-\mathrm{CD}-\mathrm{Si}$ on adsorption capacity of $\mathrm{MB}$; (b) Effect of $\mathrm{pH}$ on adsorption of methylene blue (MB) by 6-EA- $\beta$-CD-Si; (c,d) MB solutions adsorbed by 6-EA- $\beta$-CD-Si at different incubation time.

$\mathrm{pH}$ value is also one of the important factors affecting the adsorption of dyes on the adsorbent material. It affects the surface charge of $6-\mathrm{EA}-\beta-\mathrm{CD}-\mathrm{Si}$ and also affects the structure of $\mathrm{MB}$ in solution [32]. The $\mathrm{pH}$ of $\mathrm{MB}$ solution was varied from 3-12 to investigate the effect of $\mathrm{pH}$ value on the adsorption of 6-EA- $\beta-\mathrm{CD}-\mathrm{Si}$, and the results are shown in Figure $6 \mathrm{~b}$. The adsorption capacity of 6-EA- $\beta$-CD-Si onto $\mathrm{MB}$ was found to increase with a $\mathrm{pH}$ increase from 3 to 8 . At about $\mathrm{pH} 8$, the amount of adsorption displayed a slight increase. As $\mathrm{pH}$ changed from 8 to 12 , the maximum removals in the range of 98.5 to $99.2 \%$ were achieved in the range of 9 to 12 , indicating that the alkaline conditions conducive to the adsorption. This is due to the excess hydrogen ions $\left(\mathrm{H}^{+}\right)$competed with $\mathrm{MB}$ for the active sites on the surface of 6-EA- $\beta$-CD-Si [19], hindering the adsorption of 6-EA- $\beta$-CD-Si onto $\mathrm{MB}$. As the $\mathrm{pH}$ increases, the dimethylamine group becomes neutral, enhancing the interaction of $\mathrm{MB}$ molecules with the surface of 6-EA- $\beta-\mathrm{CD}-\mathrm{Si}$.

Figure $6 \mathrm{c}-\mathrm{d}$ shows the amount of $\mathrm{MB}$ adsorbed $(\mathrm{Qt}, \mathrm{mg} / \mathrm{g})$ at a specific reaction time $(\mathrm{t}, \mathrm{min})$ at $\mathrm{pH} 8( \pm 0.1)$ by 6 -EA- $\beta$-CD-Si at temperature $30^{\circ} \mathrm{C}$, respectively. It can be seen that the adsorption amounts of 6-EA- $\beta$-CD-Si onto MB increased with increasing incubation time. The adsorption amount increases rapidly within 0-10 $\mathrm{min}$, the adsorption amount increases slowly within 10-60 min, and the adsorption equilibrium was reached at an incubation time of $60 \mathrm{~min}$. Therefore, in about $10 \mathrm{~min}$, the adsorption rate of 6-EA- $\beta-\mathrm{CD}-\mathrm{Si}$ onto $\mathrm{MB}$ can reach about $80 \%$ at equilibrium, so the fast adsorption rate indicates that the internal mass transfer resistance is weak during the adsorption process [30]. The short adsorption equilibrium time indicates the high removal efficiency of 6 -EA- $\beta$-CD-Si, which is 
significant in practical applications. In addition, with the initial concentration of $\mathrm{MB}$ increasing from $20 \mathrm{mg} / \mathrm{L}$ to $100 \mathrm{mg} / \mathrm{L}$, the adsorption capacity increases from 18.86 to $51.42 \mathrm{mg} / \mathrm{g}$, indicating that the higher initial concentration will provide a more powerful driving force to overcome the mass transfer resistances between 6-EA- $\beta-\mathrm{CD}-\mathrm{Si}$ and the MB solution.

\subsection{Adsorption Kinetics}

In order to evaluate the rate-controlling step in the adsorption of $\mathrm{MB}$, the data were fitted by Pseudo-first-order kinetic model (1) and Pseudo-second-order kinetic model (2), respectively.

Pseudo-first-order kinetic model:

$$
\ln (\mathrm{Qe}-\mathrm{Qt})=\ln \mathrm{Qe}-\mathrm{K}_{1} \mathrm{t}
$$

where Qe and Qt are the adsorption capacities at equilibrium time and time $\mathrm{t}(\mathrm{mg} / \mathrm{g})$, respectively. $\mathrm{K}_{1}$ represents the pseudo-first-order kinetic model rate constant $(1 / \mathrm{min}) . \mathrm{K}_{1}$ and Qe can be gained from the slope and intercept of the $\ln (\mathrm{Qe}-\mathrm{Qt})$ versus $t$, respectively.

Pseudo-second-order kinetic model:

$$
\mathrm{t} / \mathrm{Q}_{\mathrm{t}}=-\frac{1}{\mathrm{~K}_{2} \mathrm{Qe}^{2}}+\frac{1}{\mathrm{Qe}} \mathrm{t}
$$

where $\mathrm{K}_{2}$ represents the pseudo-second-order kinetic model rate constant (g/(mg min)). Qe and $\mathrm{K}_{2}$ can be obtained from the slope and intercept of the $t / Q t$ versus $t$, respectively.

The adsorption kinetics of 6-EA- $\beta$-CD-Si were conducted with the initial concentration of $\mathrm{MB}$ from $20 \mathrm{mg} / \mathrm{L}$ to $100 \mathrm{mg} / \mathrm{L}$ and initial $\mathrm{pH}$ of $8( \pm 0.1)$. The linear fitting results for the adsorption of $\mathrm{MB}$ on 6-EA- $\beta-\mathrm{CD}-\mathrm{Si}$ are shown in Figure 7a,b. Based on the values of the linear regression coefficient $\left(R^{2}\right)$, the adsorption process of $M B$ by 6-EA- $\beta$-CD-Si was fitted better by the pseudo-second-order kinetic model $\left(\mathrm{R}^{2}=0.9896-0.9994\right)$ than by the pseudo-first-order kinetic model $\left(R^{2}=0.9024-0.9597\right)$. Furthermore, the kinetic parameters, which were calculated, are shown in Table 2. The adsorption capacity of the experimental values (Qe, exp) is very close to the value calculated from the pseudo-second-order kinetic model $(\mathrm{Qe}, \mathrm{cal})$ at five different initial concentrations. The rate constant $\left(\mathrm{K}_{2}\right)$ of pseudo-second-order kinetic model decreases with the initial concentration increasing from $20 \mathrm{mg} / \mathrm{L}$ to $100 \mathrm{mg} / \mathrm{L}$. Therefore, the reaction rate is inversely proportional to the initial concentration of $\mathrm{MB}$.
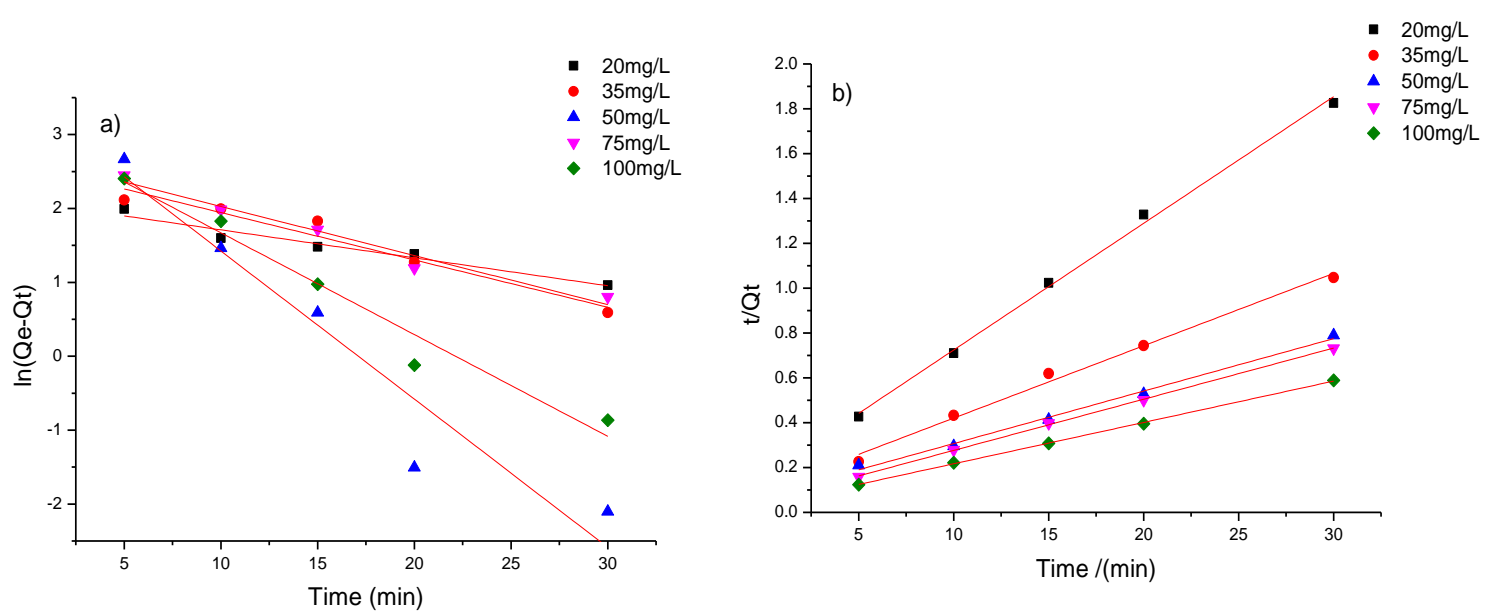

Figure 7. The linear fitting of Pseudo-first-order (a) and Pseudo-second-order (b) for removal of MB. 
Table 2. Kinetic parameters of different initial concentrations of MB.

\begin{tabular}{cccccccc}
\hline \multirow{2}{*}{$\mathbf{C}_{\mathbf{0}} \mathbf{( m g / \mathbf { L } )}$} & \multicolumn{2}{c}{ Pseudo-first-order Kinetic Model } & \multicolumn{2}{c}{ Pseudo-second-order Kinetic Model } & \\
\cline { 2 - 6 } & $\mathbf{K}_{\mathbf{1}} / \mathbf{m i n}^{-\mathbf{1}}$ & $\mathbf{Q e}, \mathbf{c a l} / \mathbf{( m g} / \mathbf{g})$ & $\mathbf{R}^{\mathbf{2}}$ & $\mathbf{K}_{\mathbf{2}} / \mathbf{m i n}^{-\mathbf{1}}$ & $\mathbf{Q e}, \mathbf{c a l} / \mathbf{( m g} / \mathbf{g})$ & $\mathbf{R}^{\mathbf{2}}$ & Qe, exp/(mg/g) \\
\hline 20 & 0.0378 & 8.0776 & 0.9391 & 0.02 & 17.7305 & 0.9966 & 18.8629 \\
35 & 0.064 & 13.2567 & 0.9387 & 0.0106 & 31.0559 & 0.9896 & 30.4405 \\
50 & 0.2004 & 30.8674 & 0.9024 & 0.0075 & 42.7351 & 0.9931 & 39.122 \\
75 & 0.0664 & 14.7508 & 0.9597 & 0.0051 & 43.8596 & 0.9993 & 43.233 \\
100 & 0.1377 & 21.0774 & 0.9549 & 0.0034 & 54.3478 & 0.9994 & 51.4216 \\
\hline
\end{tabular}

Qe, cal is the calculated equilibrium adsorption capacity, and Qe, exp is the experimental equilibrium adsorption capacity.

\subsection{Adsorption Isotherms}

Adsorption isotherms can also better simulate the adsorption behavior of MB. The Langmuir adsorption isotherm model (Equation (3)) and the Freundlich adsorption isotherm model (Equation (4)) have been used to discuss the equilibrium characteristics of the adsorption process.

The Langmuir isotherm equation can be written as

$$
\frac{\mathrm{Ce}}{\mathrm{Qe}}=\mathrm{Qmax} \times \mathrm{Ce}+\frac{1}{\left(\mathrm{Qmax} \times \mathrm{K}_{\mathrm{L}}\right)}
$$

where Ce is the equilibrium concentration of the MB solution $(\mathrm{mg} / \mathrm{L})$, Qe is the adsorption capacity of $\mathrm{MB}$ on the adsorbent at equilibrium ( $\mathrm{mg} / \mathrm{g})$, Qmax is the maximum adsorption capacity $(\mathrm{mg} / \mathrm{g})$, and $\mathrm{K}_{\mathrm{L}}$ is the Langmuir binding constant $(\mathrm{L} / \mathrm{mg})$, which is related to the free energy of adsorption. The value of Qmax and $\mathrm{K}_{\mathrm{L}}$ can be calculated from the slope and intercept of the Ce/Qe versus Ce, respectively.

Freundlich isotherm equation can be written as

$$
\operatorname{lgQe}=\frac{1}{\mathrm{n}} \lg \mathrm{Ce}+\log \mathrm{K}_{\mathrm{F}}
$$

where $K_{F}$ is the Freundlich parameter and $n$ is constant related to adsorption intensity. If $\mathrm{n}$ is greater than 1 , the adsorption process is favorable. $\mathrm{K}_{\mathrm{F}}$ and $\mathrm{n}$ can be derived from the slope and intercept of the lgQe versus $\lg$ Ce.

The equilibrium adsorption study was performed with different initial concentrations of $\mathrm{MB}$ at the temperatures $303 \mathrm{~K}, 313 \mathrm{~K}, 323 \mathrm{~K}$, and $333 \mathrm{~K}$, respectively. The slope and the intercept of each linear plot shown in Figure 8a, b. It can be found that the regression coefficient $\left(R^{2}\right)$ obtained from Freundlich model $\left(R^{2}=0.9903-0.9944\right)$ is much higher than that from Langmuir model $\left(R^{2}=0.9707-0.9858\right)$ for MB. The results suggested that the Freundlich isotherm fits better with the experimental data. The adsorption process between $\mathrm{MB}$ and material could occur on heterogeneous surfaces without being restricted to monolayers, and as the concentration of MB increase, more MB molecules can be captured on the material surfaces. Furthermore, the results fitted by Freundlich and Langmuir models are shown in Table 3. As the temperature increases, the maximum adsorption capacity decreases. The Qmax calculated from the Langmuir model is $39.37,39.21,36.90$, and $36.36 \mathrm{mg} / \mathrm{g}$ at the temperatures 303,313 , 323 , and $333 \mathrm{~K}$, respectively. Therefore, it is concluded that the temperature remarkably influences the adsorption of $\mathrm{MB}$, which indicates that adsorption is an exothermic process. Meanwhile, $\mathrm{n}$ is greater than 1 ( $n=2.0669-2.8775)$, intimating that the adsorption of MB on 6-EA- $\beta-C D-S i$ is a favorable process [33]. 

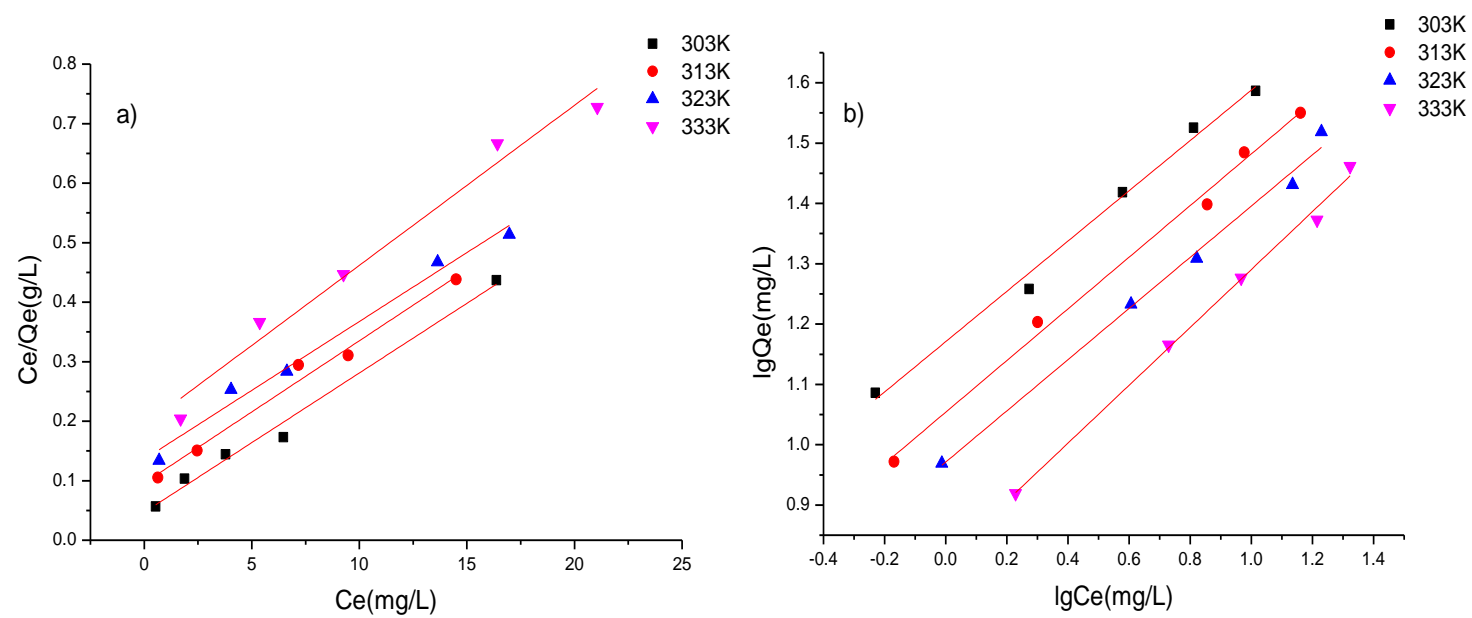

Figure 8. The equilibrium isotherms for MB adsorbed by 6-EA- $\beta-C D-S i$ : (a) the Langmuir model; (b) the Freundlich model.

Table 3. Langmuir and Freundlich isotherm fitting parameters at different temperatures.

\begin{tabular}{ccccccc}
\hline \multirow{2}{*}{$\mathbf{T}(\mathbf{K})$} & \multicolumn{2}{c}{ Langmuir Adsorption Isotherm } & \multicolumn{3}{c}{ Freundlich Adsorption Isotherm } \\
\cline { 2 - 7 } & $\mathbf{Q m a x}(\mathbf{m g} / \mathbf{g})$ & $\mathbf{K}_{\mathbf{L}} \mathbf{( L / g )}$ & $\mathbf{R}^{\mathbf{2}}$ & $\mathbf{K}_{\mathbf{F}}$ & $\mathbf{n}$ & $\mathbf{R}^{\mathbf{2}}$ \\
\hline 303 & 39.47 & 0.4790 & 0.9858 & 15.8433 & 2.8775 & 0.9927 \\
313 & 39.21 & 0.3778 & 0.9825 & 12.4202 & 2.6749 & 0.9930 \\
323 & 36.90 & 0.2691 & 0.9812 & 10.4340 & 2.6142 & 0.9903 \\
333 & 36.36 & 0.1436 & 0.9707 & 6.5337 & 2.0669 & 0.9944 \\
\hline
\end{tabular}

\subsection{Adsorption Thermodynamics}

Temperature is also a controlling parameter for MB removal. To determine the effect of 6-EA- $\beta$-CD-Si on the adsorption of MB at different temperatures, thermodynamic parameters need to be further determined and calculated by the following formula (Equations (5)-(7)). The values of enthalpy change $\left(\Delta \mathrm{H}^{\circ}\right)$ and entropy change $\left(\Delta \mathrm{S}^{\circ}\right)$ were obtained from the slope and intercept, respectively, of the graphical plot of $\operatorname{lnKd}$ as a function of $1 / \mathrm{T}$ (Figure 9).

$$
\begin{gathered}
\Delta \mathrm{G}^{\circ}=-\mathrm{RT} \ln \mathrm{Kd} \\
\ln K \mathrm{~d}=-\left(\frac{\Delta \mathrm{H}^{\circ}}{\mathrm{R}}\right)\left(\frac{1}{\mathrm{~T}}\right)+\frac{\Delta \mathrm{S}^{\circ}}{\mathrm{R}} \\
\Delta \mathrm{G}^{\circ}=\Delta \mathrm{H}^{\circ}-\mathrm{T} \Delta \mathrm{S}^{\circ}
\end{gathered}
$$

where $\Delta \mathrm{G}^{\circ}$ is the Gibbs free energy variable for the adsorption process, $\mathrm{kJ} / \mathrm{mol} ; \mathrm{Kd}$ is the isothermal adsorption constant $(\mathrm{L} / \mathrm{g}) ; \mathrm{Kd}=\mathrm{Qe} / \mathrm{Ce}$; $\mathrm{R}$ is the universal gas constant, $8.314 \mathrm{~J} /(\mathrm{mol} \cdot \mathrm{K})$; $\mathrm{T}$ is the thermodynamic temperature, $\mathrm{K} ; \Delta \mathrm{H}^{\circ}$ is the enthalpy change of the adsorption process, and $\mathrm{kJ} / \mathrm{mol}$; $\Delta \mathrm{S}^{\circ}$ is the entropy change of the adsorption process, $\mathrm{J} /(\mathrm{mol} \cdot \mathrm{K})$.

Table 4 presents the thermodynamic parameters at the initial concentration of $20 \mathrm{mg} / \mathrm{L}$ and $40 \mathrm{mg} / \mathrm{L}$ in $\mathrm{MB}$ aqueous solution. Values of the enthalpy changes $\left(\Delta \mathrm{H}^{\circ}<0 \mathrm{~kJ} / \mathrm{mol}\right)$, indicating that the adsorption of $\mathrm{MB}$ is an exothermic process, which is a good explanation for the decrease in the amount of adsorption with rising temperature appears in Table 3 , and their magnitudes $(<40 \mathrm{~kJ} / \mathrm{mol})$ means the adsorption process is mainly due to the physical adsorption in nature and the weak contact in the system [34]. The Gibbs free energy changes $\left(\Delta G^{\circ}\right)$ are negative of the tested temperatures range from $303 \mathrm{~K}$ to $333 \mathrm{~K}$, confirming that the adsorption of MB on 6-EA- $\beta-\mathrm{CD}-\mathrm{Si}$ is spontaneous and thermodynamically favorable [35]. The values of $\Delta \mathrm{G}^{\circ}$ are among -15.6178 and $-11.2937 \mathrm{~kJ} / \mathrm{mol}$, 
which further indicating that the physical adsorption might dominate the adsorption of $\mathrm{MB}$ on 6 -EA- $\beta$-CD-Si, along with the weak interactions between MB and 6-EA- $\beta$-CD-Si.

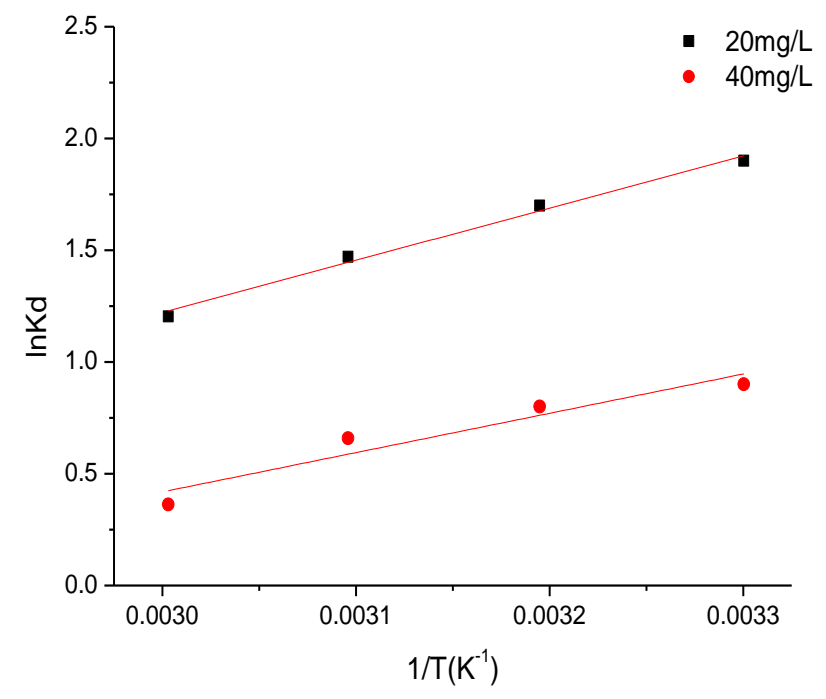

Figure 9. Liner plot of $\ln \mathrm{K}_{\mathrm{d}}$ versus $1 / \mathrm{T}$ for the adsorption of MB.

Table 4. Adsorption thermodynamic parameters at different temperatures.

\begin{tabular}{ccccc}
\hline $\mathbf{C o}(\mathbf{m g} / \mathrm{L})$ & $\mathbf{T}(\mathbf{K})$ & $\boldsymbol{\Delta} \mathbf{G}^{\circ} \mathbf{( k J / m o l )}$ & $\boldsymbol{\Delta} \mathbf{H}^{\circ} \mathbf{( k J / m o l )}$ & $\Delta \mathbf{S}^{\circ}\left(\mathbf{J} \cdot \mathbf{m o l}^{-\mathbf{1}} \cdot \mathbf{K}^{-\mathbf{1}}\right)$ \\
\hline \multirow{2}{*}{20} & 303 & -15.6178 & & \\
& 313 & -15.4931 & -19.3966 & -12.4710 \\
& 323 & -15.3684 & & \\
& 333 & -15.2437 & & -9.9768 \\
40 & 303 & -11.5930 & & \\
& 313 & -11.4933 & -14.616 & \\
& 323 & -11.3935 & & \\
\hline
\end{tabular}

\subsection{Adsorption Mechanism}

Through the above study of adsorption kinetics, adsorption isotherms, thermodynamic analysis, and optimum $\mathrm{pH}$ conditions, the $\mathrm{MB}$ adsorption mechanism can be inferred. To verify the adsorption mechanism, the FT-IR spectra of MB, 6-EA- $\beta-\mathrm{CD}-\mathrm{Si}$, and 6-EA- $\beta-\mathrm{CD}-\mathrm{Si} / \mathrm{MB}$ are shown in Figure 10a. After the adsorption of MB onto 6-EA- $\beta$-CD-Si, the FT-IR spectra exhibits many changes. It is found that the appearance of peaks at $1602 \mathrm{~cm}^{-1}, 1489 \mathrm{~cm}^{-1}$, and $1394 \mathrm{~cm}^{-1}$ in the FT-IR spectra of 6-EA- $\beta$-CD-Si after adsorption of $\mathrm{MB}$, which belongs to the stretching vibrations of $\mathrm{C}=\mathrm{C}$ in benzene rings and the $\mathrm{C}-\mathrm{N}$ stretching vibration existing on the $\mathrm{MB}$ molecules. Thus, there is the interaction between $\mathrm{MB}$ and 6 -EA- $\beta$-CD-Si, which is a hydrogen bond. The adsorption mechanism of MB onto 6-EA- $\beta$-CD-Si can be summarized as shown in Figure 10b. Based on the analysis above, the adsorption mechanism is attributed to the host-guest interactions between cyclodextrin and aromatic molecules, the electrostatic interactions, and weak hydrogen bonding between $\mathrm{MB}$ and 6-EA- $\beta$-CD-Si.

Table 5 contrasts this study on the adsorption of MB to those in previous literature and revealed that 6-EA- $\beta$-CD-Si shows a greater adsorption capability comparing with other adsorbents, including activated carbon and some other low-cost adsorbents. However, the adsorption mechanisms between $\mathrm{MB}$ and the adsorbents reported by other researchers were unknown. In this work, through the detailed discussion, it can be found that the removal mechanism of MB by 6-EA- $\beta$-CD-Si is mainly due to the host-guest interactions, the electrostatic interactions, and weak hydrogen bonding between 6 -EA- $\beta$-CD-Si and MB. These results indicated that the 6-EA- $\beta$-CD-Si core-shell nanomaterial could be 
considered as a promising adsorbent for the removal of $\mathrm{MB}$ from wastewater. At the end of the third cycle, the adsorption rate of MB on 6-EA- $\beta$-CD-Si can still reach $65 \%$ (data not shown). Furthermore, the processes of adsorption, separation and desorption with 6-EA- $\beta$-CD-Si avoids the secondary pollution of water and improve the adsorption efficiency of dyes compared with the previous.
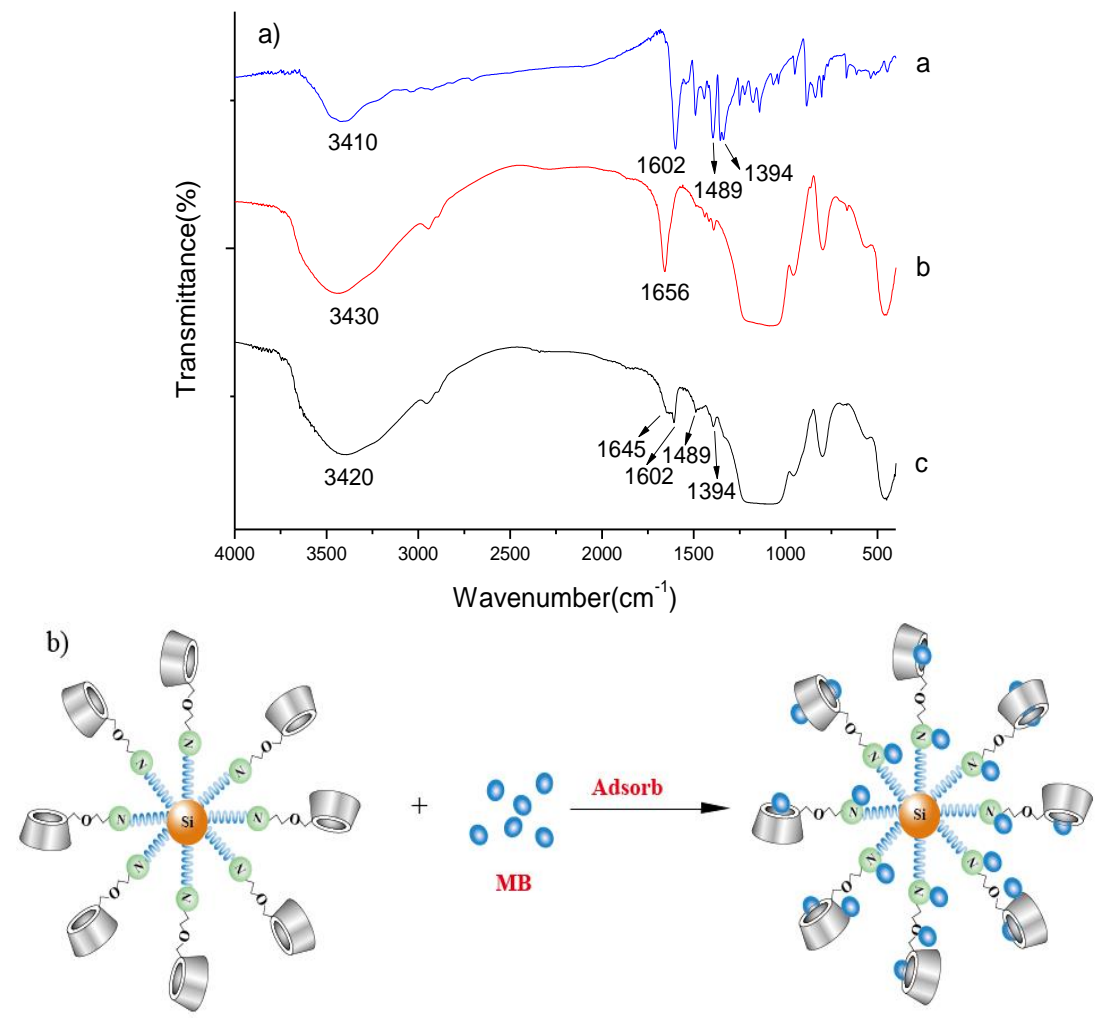

Figure 10. (a) FT-IR spectroscopy of (a) MB, (b) 6-EA- $\beta$-CD-Si, (c) 6-EA- $\beta$-CD-Si/MB; (b) Speculated adsorption mechanism of MB onto 6-EA- $\beta$-CD-Si.

Table 5. Adsorption isotherms of MB on various adsorbents.

\begin{tabular}{|c|c|c|c|c|c|}
\hline Adsorbents & $\begin{array}{l}\text { BET Surface } \\
\text { Area }\left(\mathrm{m}^{2} / \mathrm{g}\right)\end{array}$ & Isotherm & $\begin{array}{c}\text { Adsorption Capacity, } \\
\text { Qm (mg/g) }\end{array}$ & $\mathrm{pH}$ & Reference \\
\hline sodium hydroxide & 31.35 & Langmuir & 27.86 & - & [36] \\
\hline $\begin{array}{l}\text { phenyl-functionalized } \\
\text { silica materials } \\
\text { magnetic }\end{array}$ & - & Sips & 33.7 & 8 & [37] \\
\hline $\begin{array}{l}\text { graphene-carbon } \\
\text { nanotube }\end{array}$ & - & Langmuir & 24.88 & 7 & [38] \\
\hline clay & 30 & Freundlich & 6.3 & - & [39] \\
\hline $\begin{array}{l}\text { activated carbon from } \\
\text { waste biomass }\end{array}$ & 240.02 & Langmuir & 16.43 & 6 & [30] \\
\hline $\begin{array}{c}\text { vegetal fiber activated } \\
\text { carbons }\end{array}$ & - & - & 33.7 & 10 & [40] \\
\hline $\begin{array}{l}\text { cyclodextrin-functionalized } \\
\text { hybrid silicon }\end{array}$ & 240 & Freundlich & 39.47 & 8 & This work \\
\hline
\end{tabular}

\section{Materials and Methods}

\subsection{Preparation of $6-E A-\beta-C D$}

2-chloroethylamine hydrochloride (1.5 g) was sonicated and dispersed in double-distilled water $(6 \mathrm{~mL}) \cdot \beta-\mathrm{CD}(15 \mathrm{~g})$ was added to the dispersion and dried at $50{ }^{\circ} \mathrm{C}$ until the water was completely 
evaporated. The product was added to $\mathrm{NaOH}$ solution (10\%), and the reaction was stirred for $240 \mathrm{~min}$ at $70{ }^{\circ} \mathrm{C}$. After the reaction, the product was precipitated with methanol, filtered and washed three times and dried at $40{ }^{\circ} \mathrm{C}$ for $6 \mathrm{~h}$ to obtain $6-\mathrm{EA}-\beta-\mathrm{CD}$.

\subsection{Preparation of $\mathrm{Cl}-\mathrm{Si}$}

The synthesis of Cl-Si was slightly modified according to the method previously reported [26]. 3-Chloropropyl-triethoxysilane (CPTES) $(4.78 \mathrm{~mL})$ and tetraethyl orthosilicate (TEOS) (22 mL) were fully dissolved in anhydrous ethanol $(60 \mathrm{~mL})$. Ultrapure water $(7.2 \mathrm{~mL})$ and $1 \mathrm{M}$ tetrabutylammonium fluoride in THF $(6 \mathrm{~mL})$ were dissolved in another absolute ethanol solution $(40 \mathrm{~mL})$, and then the two mixtures were thoroughly mixed for $10 \mathrm{~s}$ to obtain a homogenous solution. Gel was observed after $30 \mathrm{~min}$ and aged at room temperature for six days. The obtained gel was crushed, filtered, and washed successively with ethanol and acetone solution. Thus, the material was dried at $80{ }^{\circ} \mathrm{C}$ for $6 \mathrm{~h}$ to obtain Cl-Si as a white powder.

\subsection{Preparation of $6-E A-\beta-C D-S i$}

The 6-EA- $\beta$-CD-Si was prepared as following methods: 6-EA- $\beta$-CD (3 g), Cl-Si (2 g), and KI (0.2 g) were dissolved in DMF $(60 \mathrm{~mL})$, nitrogen gas was blown into the reaction vessel for 5 min so that air in the reaction vessel was discharged, and the reaction was stirred at $110{ }^{\circ} \mathrm{C}$ for $24 \mathrm{~h}$. After the reaction was completed, the mixtures were cooled to room temperature, and the suspension was filtered and washed successively with DMF, ethanol, and water, and then the obtained material was dried under vacuum at $60{ }^{\circ} \mathrm{C}$ for $9 \mathrm{~h}$ to obtain 6 -EA- $\beta$-CD-Si as a white power.

\subsection{Samples Characterization}

Fourier transform infrared spectrometer was carried out using a Nicolet 5700 spectrometer (Thermo Fisher Scientific, Waltham, MA, USA), and spectra were recorded between 500 and $4000 \mathrm{~cm}^{-1}$. The X-ray diffraction spectrometer (XRD) experiments were recorded on an X-ray diffraction spectrometer using $\mathrm{Cu} \mathrm{K} \alpha 1.5406 \AA$ in the scattering angle range of $2 \theta=5$ to $50^{\circ}$. The SEM images of 6 -EA- $\beta$-CD-Si were taken using a scanning electron microscope. Thermal stability was analyzed by a thermogravimetric analyzer in the air atmosphere with the airflow rate of $50 \mathrm{~cm}^{3} / \mathrm{min}$. The temperature was ranged from 30 to $700{ }^{\circ} \mathrm{C}$ at a scanning rate of $10^{\circ} \mathrm{C} / \mathrm{min}$. The Brunauer-Emmett-Teller (BET) surface area analyses of the sample were performed using a low-temperature $\mathrm{N}_{2}$ adsorption-desorption technique with a Micromeritics ASAP 2020 (Micromeritics, Orlando, FL, USA) gas adsorption apparatus. The particle size of as-synthesized nanoparticles was measured using a Nanoparticle size and zeta potential analysis Uptake was determined by measuring the reduction in absorbance or depletion from solution using UV-vis spectrophotometry at the wavelength $660 \mathrm{~nm}$.

\subsection{Adsorption of Anionic Dyes}

The adsorption behaviors of 6-EA- $\beta-\mathrm{CD}-\mathrm{Si}$ were systematically investigated by changing the factors of adsorbent dosage, $\mathrm{pH}$ value, adsorption time, initial concentration, and adsorption temperature. The specific experimental process is as follow: The process of adsorption was performed in bath thermostatic shaker with a certain temperature at a speed of $210 \mathrm{rpm}$. After the adsorption reaction was completed, the supernatant solution was taken after centrifugation at 10,000 rpm for $15 \mathrm{~min}$, and the residual concentration of MB was determined by UV-vis spectrophotometry at the wavelength $660 \mathrm{~nm}$.

The adsorption capacity Equation (8) and removal rate Equation (9) were calculated according to the following formulas:

$$
\begin{aligned}
& \mathrm{Qe}=\left(\mathrm{C}_{0}-\mathrm{C}_{\mathrm{e}}\right) / \mathrm{C}_{0} \times \mathrm{V} / \mathrm{m} \\
& \mathrm{E}(\%)=\left(\mathrm{C}_{0}-\mathrm{C}_{\mathrm{e}}\right) / \mathrm{C}_{0} \times 100
\end{aligned}
$$


where Qe $(\mathrm{mg} / \mathrm{g})$ is the adsorbed amount of MB on 6-EA- $\beta$-CD-Si. $\mathrm{C}_{0}(\mathrm{mg} / \mathrm{L})$ and Ce $(\mathrm{mg} / \mathrm{L})$ are the initial and real-time concentrations of $\mathrm{MB}$, respectively. $\mathrm{V}(\mathrm{mL})$ is the volume of solution, and $\mathrm{m}(\mathrm{mg})$ is the mass of 6-EA- $\beta-C D-S i$ used.

\section{Conclusions}

In summary, a novel cyclodextrin-functionalized hybrid silicon nano-adsorbent core-shell material (6-EA- $\beta$-CD-Si) was successfully prepared via the nucleophilic substitution method, and the removal of $\mathrm{MB}$ in an aqueous solution was studied. The adsorption results confirm that 6 -EA- $\beta$-CD-Si is an effective adsorbent and exhibited good adsorption property toward methylene blue (MB). The best $\mathrm{pH}$ value for adsorption of $\mathrm{MB}$ is 10.5 with maximum removal efficiency of $99.2 \%$. The result of kinetic study shows that pseudo-second-order kinetic model is the best kinetic model for describing of MB adsorption onto 6-EA- $\beta$-CD-Si and maximum $99.5 \%$ removal was achieved during adsorption kinetic study. The equilibrium data were well-modeled by the Freundlich isotherm model, and the thermodynamic parameters indicated that the adsorption process of MB onto 6-EA- $\beta$-CD-Si was a spontaneous and exothermic process. The host-guest interactions between 6-EA- $\beta$-CD-Si and aromatic molecules, the electrostatic interactions, and weak hydrogen bonding between $\mathrm{MB}$ and 6-EA- $\beta$-CD-Si are essential for the adsorption of MB. The above results confirmed the potential of $6-E A-\beta-C D-S i$ as an efficient adsorbent material with advantages of widespread availability, environmental friendliness, and low cost in separating dye from solution. Thus, 6-EA- $\beta$-CD-Si has great potential applications in industrial wastewater treatment and environmental protection.

Author Contributions: Conceptualization, J.L. and J.W.; Methodology, J.L.; Software, C.Q.; Validation, H.F., Y.B. and Z.J.; Formal Analysis, J.L.; Investigation, J.W.; Resources, Y.B.; Data Curation, C.Q.; Writing-Original Draft Preparation, J.L.; Writing-Review and Editing, J.W.; Visualization, Z.J.; Supervision, J.W.; Project Administration, J.W.; Funding Acquisition, J.W.

Acknowledgments: This project was supported financially by the National Key Research and Development Program (2017YFC1601000, 2016YFD0400304) and the Natural Science Foundation of Jiangsu Province (BK20140143). National first-class discipline program of Food Science and Technology (JUFSTR20180203).

Conflicts of Interest: The authors declare no conflict of interest.

\section{References}

1. Fu, F.; Wang, Q. Removal of heavy metal ions from wastewaters: A review. J. Environ. Manag. 2011, 92, 407-418. [CrossRef] [PubMed]

2. Qiao, H.; Zhou, Y.; Yu, F.; Wang, E.; Min, Y.; Huang, Q.; Pang, L.; Ma, T. Effective removal of cationic dyes using carboxylate-functionalized cellulose nanocrystals. Chemosphere 2015, 141 (Suppl. C), $297-303$. [CrossRef] [PubMed]

3. Wang, Y.; Gai, L.; Ma, W.; Jiang, H.; Peng, X.; Zhao, L. Ultrasound-assisted catalytic degradation of methyl orange with $\mathrm{Fe}_{3} \mathrm{O}_{4}$ /polyaniline in near neutral solution. Ind. Eng. Chem. Res. 2015, 54, 2279-2289. [CrossRef]

4. Herrero, M.; Stuckey, D.C. Bioaugmentation and its application in wastewater treatment: A review. Chemosphere 2015, 140 (Suppl. C), 119-128. [CrossRef] [PubMed]

5. Yuan, H.; Xu, C.; Zhu, N. Disinhibition of the ammonium nitrogen in autothermal thermophilic aerobic digestion for sewage sludge by chemical precipitation. Bioresour. Technol. 2014, 169 (Suppl. C), 686-691. [CrossRef] [PubMed]

6. Dasgupta, J.; Sikder, J.; Chakraborty, S.; Curcio, S.; Drioli, E. Remediation of textile effluents by membrane based treatment techniques: A state of the art review. J. Environ. Manag. 2015, 147 (Suppl. C), 55-72. [CrossRef] [PubMed]

7. Panić, V.V.; Šešlija, S.; Nešić, A.R.; Veličković, S.J. Adsorption of azo dyes on polymer materials. Hemijska Industrija 2013, 67, 881-900. [CrossRef]

8. Gouamid, M.; Ouahrani, M.R.; Bensaci, M.B. Adsorption equilibrium, kinetics and thermodynamics of methylene blue from aqueous solutions using date palm leaves. Energy Procedia 2013, 36 (Suppl. C), 898-907. [CrossRef] 
9. Li, B.; Feng, Y.L.; Guo, J.Z.; Bai, L.Q.; Chen, J.; Liu, L.; Zhang, L.J. An amorphous coordination polymer with high adsorption ability for anionic dyes from aqueous solution. Sci. Adv. Mater. 2013, 5, 341-345. [CrossRef]

10. Yousef, R.I.; El-Eswed, B.; Al-Muhtaseb, A.a.H. Adsorption characteristics of natural zeolites as solid adsorbents for phenol removal from aqueous solutions: Kinetics, mechanism, and thermodynamics studies. Chem. Eng. J. 2011, 171, 1143-1149. [CrossRef]

11. Guo, X.; Wei, Q.; Du, B.; Zhang, Y.; Xin, X.; Yan, L.; Yu, H. Removal of basic dyes (malachite green) from aqueous medium by adsorption onto amino functionalized graphenes in batch mode. Des. Water Treat. 2015, 53, 818-825. [CrossRef]

12. Debnath, S.; Kitinya, J.; Onyango, M.S. Removal of Congo red from aqueous solution by two variants of calcium and iron based mixed oxide nano-particle agglomerates. J. Ind. Eng. Chem. 2014, 20, 2119-2129. [CrossRef]

13. Fayazi, M.; Afzali, D.; Taher, M.A.; Mostafavi, A.; Gupta, V.K. Removal of Safranin dye from aqueous solution using magnetic mesoporous clay: Optimization study. J. Mol. Liq. 2015, 212 (Suppl. C), 675-685. [CrossRef]

14. Demirbas, A. Agricultural based activated carbons for the removal of dyes from aqueous solutions: A review. J. Hazard. Mater. 2009, 167, 1-9. [CrossRef] [PubMed]

15. Kizilkaya, B.; Tekinay, A.A. Comparative study and removal of $\mathrm{Co}$ and $\mathrm{Ni}$ (II) ions from aqueous solutions using fish bones. Sci. Adv. Mater. 2011, 3, 949-961. [CrossRef]

16. Wang, N.; Zhou, L.; Guo, J.; Ye, Q.; Lin, J.-M.; Yuan, J. Adsorption of environmental pollutants using magnetic hybrid nanoparticles modified with $\beta$-cyclodextrin. Appl. Surf. Sci. 2014, 305 (Suppl. C), 267-273. [CrossRef]

17. Debnath, S.; Ballav, N.; Maity, A.; Pillay, K. Competitive adsorption of ternary dye mixture using pine cone powder modified with $\beta$-cyclodextrin. J. Mol. Liq. 2017, 225 (Suppl. C), 679-688. [CrossRef]

18. Arima, H.; Motoyama, K.; Higashi, T. Potential Use of cyclodextrins as drug carriers and active pharmaceutical ingredients. Chem. Pharm. Bull. 2017, 65, 341. [CrossRef] [PubMed]

19. Badruddoza, A.Z.M.; Shawon, Z.B.Z.; Tay, W.J.D.; Hidajat, K.; Uddin, M.S. $\mathrm{Fe}_{3} \mathrm{O}_{4}$ / cyclodextrin polymer nanocomposites for selective heavy metals removal from industrial wastewater. Carbohydr. Polym. 2013, 91, 322-332. [CrossRef] [PubMed]

20. Liu, W.; Jiang, X.; Chen, X. A novel method of synthesizing cyclodextrin grafted multiwall carbon nanotubes/iron oxides and its adsorption of organic pollutant. Appl. Surf. Sci. 2014, 320 (Suppl. C), 764-771. [CrossRef]

21. Kiasat, A.R.; Nazari, S. $\beta$-Cyclodextrin conjugated magnetic nanoparticles as a novel magnetic microvessel and phase transfer catalyst: Synthesis and applications in nucleophilic substitution reaction of benzyl halides. J. Incl. Phenom. Macrocycl. Chem. 2013, 76, 363-368. [CrossRef]

22. Michalska, K.; Gruba, E.; Bocian, W.; Cielecka-Piontek, J. Enantioselective recognition of radezolid by cyclodextrin modified capillary electrokinetic chromatography and electronic circular dichroism. J. Pharm. Biomed. Anal. 2017, 139 (Suppl. C), 98-108. [CrossRef] [PubMed]

23. Shvets, O.; Belyakova, L. Synthesis, characterization and sorption properties of silica modified with some derivatives of $\beta$-cyclodextrin. J. Hazard. Mater. 2015, 283 (Suppl. C), 643-656. [CrossRef] [PubMed]

24. Cai, D.; Zhang, T.; Zhang, F.; Luo, X. Quaternary ammonium $\beta$-cyclodextrin-conjugated magnetic nanoparticles as nano-adsorbents for the treatment of dyeing wastewater: Synthesis and adsorption studies. J. Environ. Chem. Eng. 2017, 5, 2869-2878. [CrossRef]

25. Tan, P.; Hu, Y. Improved synthesis of graphene/ $\beta$-cyclodextrin composite for highly efficient dye adsorption and removal. J. Mol. Liq. 2017, 242 (Suppl. C), 181-189. [CrossRef]

26. Borja, G.; Monge-Marcet, A.; Pleixats, R.; Parella, T.; Cattoën, X.; Man, M.W.C. Recyclable hybrid silica-based catalysts derived from Pd-NHC complexes for Suzuki, Heck and Sonogashira reactions. Eur. J. Org. Chem. 2012, 3625-3635. [CrossRef]

27. Akçakoca Kumbasar, E.P.; Akduman, Ç.; Çay, A. Effects of $\beta$-cyclodextrin on selected properties of electrospun thermoplastic polyurethane nanofibres. Carbohydr. Polym. 2014, 104 (Suppl. C), 42-49. [CrossRef] [PubMed]

28. Zhu, L.; O’Dwyer, J.P.; Chang, V.S.; Granda, C.B.; Holtzapple, M.T. Structural features affecting biomass enzymatic digestibility. Bioresour. Technol. 2008, 99, 3817-3828. [CrossRef] [PubMed] 
29. Zhao, D.; Zhao, L.; Zhu, C.S.; Huang, W.Q.; Hu, J.L. Water-insoluble $\beta$-cyclodextrin polymer crosslinked by citric acid: Synthesis and adsorption properties toward phenol and methylene blue. J. Incl. Phenom. Macrocycl. Chem. 2009, 63, 195-201. [CrossRef]

30. Karagöz, S.; Tay, T.; Ucar, S.; Erdem, M. Activated carbons from waste biomass by sulfuric acid activation and their use on methylene blue adsorption. Bioresour. Technol. 2008, 99, 6214-6222. [CrossRef] [PubMed]

31. Ebadi, A.; Rafati, A.A. Preparation of silica mesoporous nanoparticles functionalized with $\beta$-cyclodextrin and its application for methylene blue removal. J. Mol. Liq. 2015, 209, 239-245. [CrossRef]

32. Dil, A.E.; Ghaedi, M.; Asfaram, A.; Hajati, S.; Mehrabi, F.; Goudarzi, A. Preparation of nanomaterials for the ultrasound-enhanced removal of $\mathrm{Pb}^{2+}$ ions and malachite green dye: Chemometric optimization and modeling. Ultrason. Sonochem. 2017, 34 (Suppl. C), 677-691. [CrossRef] [PubMed]

33. Cheng, C.; Ma, L.; Ren, J.; Li, L.; Zhang, G.; Yang, Q.; Zhao, C. Preparation of polyethersulfone-modified sepiolite hybrid particles for the removal of environmental toxins. Chem. Eng. J. 2011, 171, 1132-1142. [CrossRef]

34. Kara, M.; Yuzer, H.; Sabah, E.; Celik, M.S. Adsorption of cobalt from aqueous solutions onto sepiolite. Water Res. 2003, 37, 224-232. [CrossRef]

35. Fernandes, A.N.; Almeida, C.A.P.; Debacher, N.A.; de Souza Sierra, M.M. Isotherm and thermodynamic data of adsorption of methylene blue from aqueous solution onto peat. J. Mol. Struct. 2010, 982, 62-65. [CrossRef]

36. Zhang, J.; Ping, Q.; Niu, M.; Shi, H.; Li, N. Kinetics and equilibrium studies from the methylene blue adsorption on diatomite treated with sodium hydroxide. Appl. Clay Sci. 2013, 83-84, 12-16. [CrossRef]

37. Saad, N.; Almawla, M.; Moubarak, E.; Alghoul, M.; Elrassy, H. Surface-functionalized silica aerogels and alcogels for methylene blue adsorption. RSC Adv. 2014, 5, 6111-6122. [CrossRef]

38. Wang, P.; Cao, M.; Wang, C.; Ao, Y.; Hou, J.; Qian, J. Kinetics and thermodynamics of adsorption of methylene blue by a magnetic graphene-carbon nanotube composite. Appl. Surf. Sci. 2014, 290 (Suppl. C), 116-124. [CrossRef]

39. Gürses, A.; Karaca, S.; Doğar, Ç.; Bayrak, R.; Açıkyıldız, M.; Yalçın, M. Determination of adsorptive properties of clay/water system: Methylene blue sorption. J. Colloid Interface Sci. 2004, 269, 310-314. [CrossRef] [PubMed]

40. Cherifi, H.; Fatiha, B.; Salah, H. Kinetic studies on the adsorption of methylene blue onto vegetal fiber activated carbons. Appl. Surf. Sci. 2013, 282 (Suppl. C), 52-59. [CrossRef]

Sample Availability: Samples of the compounds are available from the authors.

(C) 2018 by the authors. Licensee MDPI, Basel, Switzerland. This article is an open access article distributed under the terms and conditions of the Creative Commons Attribution (CC BY) license (http:/ / creativecommons.org/licenses/by/4.0/). 